\title{
Chemical Composition, Biological Activity, and Health-Promoting Effects of Withania somnifera for Pharma- Food Industry Applications
}

\author{
Javad Sharifi-Rad ${ }^{\mathbb{D}},{ }^{1}$ Cristina Quispe, ${ }^{2}$ Seyed Abdulmajid Ayatollahi ${ }^{1},{ }^{1,3}$ \\ Farzad Kobarfard, ${ }^{1,4}$ Mariola Staniak, ${ }^{5}$ Anna Stępień, ${ }^{5}$ Katarzyna Czopek, ${ }^{5}$ Surjit Sen, ${ }^{6,7}$ \\ Krishnendu Acharya, ${ }^{6}$ Karl R. Matthews, ${ }^{8}$ Bilge Sener, ${ }^{9}$ Hari Prasad Devkota ${ }^{\mathbb{D}},{ }^{10}$ \\ Celale Kırkın, ${ }^{11}$ Beraat Özçelik $\mathbb{D}^{1},{ }^{11,12}$ Montserrat Victoriano, ${ }^{13}$ Miquel Martorell $\mathbb{D}^{\mathrm{D}},{ }^{13,14}$ \\ Hafiz Ansar Rasul Suleria (D), ${ }^{15}$ Mohammed M. Alshehri $\mathbb{D}^{16},{ }^{16}$ Deepak Chandran, ${ }^{17}$ \\ Manoj Kumar, ${ }^{18}$ Natália Cruz-Martins $\mathbb{D},,^{19,20,21,22}$ and William C. Cho $\mathbb{D}^{23}$ \\ ${ }^{1}$ Phytochemistry Research Center, Shahid Beheshti University of Medical Sciences, Tehran, Iran \\ ${ }^{2}$ Facultad de Ciencias de la Salud, Universidad Arturo Prat, Avda. Arturo Prat 2120, Iquique 1110939, Chile \\ ${ }^{3}$ Department of Pharmacognosy and Biotechnology, School of Pharmacy, Shahid Beheshti University of Medical Sciences, \\ Tehran, Iran \\ ${ }^{4}$ Department of Medicinal Chemistry, School of Pharmacy, Shahid Beheshti University of Medical Sciences, Tehran, Iran \\ ${ }^{5}$ Institute of Soil Science and Plant Cultivation-State Research Institute, Czartoryskich 8, Puławy 24-100, Poland \\ ${ }^{6}$ Molecular and Applied Mycology and Plant Pathology Laboratory, Department of Botany, University of Calcutta, \\ Kolkata 700019, India \\ ${ }^{7}$ Department of Botany, Fakir Chand College, Diamond Harbour, West Bengal 743331, India \\ ${ }^{8}$ Department of Food Science, Rutgers University, New Brunswick, New Jersey, USA \\ ${ }^{9}$ Gazi University, Faculty of Pharmacy, Department of Pharmacognosy, Ankara 06330, Turkey \\ ${ }^{10}$ Graduate School of Pharmaceutical Sciences, Kumamoto University, 5-1 Oe-honmachi, Kumamoto 862-0973, Japan \\ ${ }^{11}$ Department Food Engineering, Faculty of Chemical and Metallurgical Engineering, Istanbul Technical University, Maslak, \\ Istanbul 34469, Turkey \\ ${ }^{12}$ Bioactive Research \& Innovation Food Manufacturing Industry Trade Ltd. Co., Maslak, Istanbul 34469, Turkey \\ ${ }^{13}$ Department of Nutrition and Dietetics, Faculty of Pharmacy, University of Concepción, Concepción 4070386, Chile \\ ${ }^{14}$ Centre for Healthy Living, University of Concepción, Concepción 4070386, Chile \\ ${ }^{15}$ Department of Agriculture and Food Systems, The University of Melbourne, Melbourne 3010, Australia \\ ${ }^{16}$ Pharmaceutical Care Department, Ministry of National Guard-Health Affairs, Riyadh, Saudi Arabia \\ ${ }^{17}$ Department of Veterinary Sciences and Animal Husbandry, Amrita School of Agricultural Sciences, \\ Amrita Vishwa Vidyapeetham University, Coimbatore 642109, India \\ ${ }^{18}$ Chemical and Biochemical Processing Division, ICAR-Central Institute for Research on Cotton Technology, \\ Mumbai 400019, India \\ ${ }^{19}$ Faculty of Medicine, University of Porto, Porto, Portugal \\ ${ }^{20}$ Institute for Research and Innovation in Health (i3S), University of Porto, Porto, Portugal \\ ${ }^{21}$ Institute of Research and Advanced Training in Health Sciences and Technologies (CESPU), Rua Central de Gandra, 1317, \\ Gandra 4585-116, Portugal \\ ${ }^{22}$ TOXRUN-Toxicology Research Unit, University Institute of Health Sciences, CESPU, CRL, 4585-116 Gandra, Portugal \\ ${ }^{23}$ Department of Clinical Oncology, Queen Elizabeth Hospital, Kowloon, Hong Kong
}

Correspondence should be addressed to Javad Sharifi-Rad; javad.sharifirad@gmail.com, Hari Prasad Devkota; devkotah@ gpo.kumamoto-u.ac.jp, Miquel Martorell; mmartorell@udec.cl, Natália Cruz-Martins; ncmartins@med.up.pt, and William C. Cho; chocs@ha.org.hk

Received 9 July 2021; Revised 19 October 2021; Accepted 10 December 2021; Published 29 December 2021

Academic Editor: Sobhy El-Sohaimy 
Copyright (C) 2021 Javad Sharifi-Rad et al. This is an open access article distributed under the Creative Commons Attribution License, which permits unrestricted use, distribution, and reproduction in any medium, provided the original work is properly cited.

\begin{abstract}
The Withania genus comes from the Solanaceae family and includes around 23 species, spread over some areas of the Mediterranean, Asia, and East Africa. Widely used in traditional medicine for thousands of years, these plants are rich in secondary metabolites, with special emphasis on steroidal lactones, named withanolides which are used as ingredients in numerous formulations for a plethora of diseases, such as asthma, diabetes, arthritis, impotence, amnesia, hypertension, anxiety, stress, cancer, neurodegenerative, and cardiovascular diseases, and many others. Among them, Withania somnifera (L.) Dunal is the most widely addressed species from a pharmacological and agroindustrial point of view. In this sense, this review provides an overview of the folk uses, phytochemical composition, and biological activity, such as antioxidant, antimicrobial, anti-inflammatory, and cytotoxic activity of $W$. somnifera, although more recently other species have also been increasingly investigated. In addition, their health-promoting effects, i.e., antistress, anxiolytic, adaptogenic, antirheumatoid arthritis, chemoprotective, and cardiorespiratory-enhancing abilities, along with safety and adverse effects are also discussed.
\end{abstract}

\section{Introduction}

The genus Withania (Solanaceae) includes 23 species [1], mostly occurring in North Africa, Canary Islands, Southern Europe, and Asia (Figure 1) [2-7]. Of the known species, there are two of huge economic importance that are also mostly grown due to their wide applicability in natural medicine [8], namely, Withania somnifera (L.) Dunal and Withania coagulans (Stocks) Dunal. Both species are grown mainly in subtropical regions of India. However, $W$. somnifera even presents a greater economic significance $[9,10]$. In Morocco and Algeria, Withania adpressa Cors. is also found as an endemic species [11], although both the morphological form and phytochemical composition of such plants undergo polymorphisms, conditioned by its occurrence in a given geographical area [5].

Although various Withania spp. have been used in traditional medicine for the management of different pathologies [12], W. somnifera and W. coagulans are the most widely recognized species not only for their economic value but also for their therapeutic potential, and they are largely commercialized and cultivated in Afghanistan, Iran, India, and Pakistan [13-20]. In this sense, this review aims to provide an overview of the botanical features, traditional uses, phytochemical composition, biological activities, and health-promoting effects observed in preclinical and clinical studies of W. somnifera, along with updated data on its safety and adverse effects.

\section{Botanical Features}

Plants under the Withania genus are evergreen with heights ranging from 0.5 to $2.0 \mathrm{~m}$, present grasses, bush suburbs, branched or unbranched [21, 22]. The flowers are green or yellow, little pedicelled or pentameric umbels, sessile to subsessile, and hermaphrodites. They have simple leaves, petiolate, ovate, alternate, or in unequal pairs with a sharp apex. Fruits are berry of $6 \mathrm{~mm}$ in diameter, with orange-red color when mature, globous, and enclosed in the green calyx. Seeds are compressed, small, flat, yellow, reniform, reticulate to smooth, and very light $[2,23-28]$.

\section{Traditional Uses}

From a folk medicinal point of view, $W$. somnifera, known as "winter cherry," is the most important species belonging to the Withania genus, and that evidences the most renowned therapeutic abilities. This plant has been used in Indian medicine for a long time, and its roots are used in more than 200 formulations $[2,29,30]$.

W. somnifera (called Ashwagandha, Indian ginseng) is the best-known species, widely used in natural medicine as it helps in many different ailments, namely, in boosting the immune and hematopoietic system, has an anti-inflammatory activity that helps in skin diseases and osteoarthritis, and also has antiaging effects. In addition, it is also used in hypothyroidism, cardiovascular diseases, diabetes, depression, and chronic stress [31, 32]. More recently, several clinical trials have also confirmed their therapeutic uses, namely, in the treatment of anxiety, insomnia, and Parkinson's disease [33]. In Ayurveda, W. somnifera is used for over 3000 years [9] and is considered to have excellent rejuvenating abilities, while it prolongs life and has strong aphrodisiac effects. Indeed, this plant is traditionally used in India to promote youthful vigor, strength, endurance, and health $[20,33]$, so that such restorative properties have led to $W$. somnifera roots being called Indian ginseng. $W$. somnifera may also be useful to treat various central nervous system (CNS) disorders, such as epilepsy, stress, and neurodegenerative conditions, like Parkinson's disease (PD), Alzheimer's disease (AD), and even cerebral ischemia. Ethnobotanically, it can be used as a hallucinogenic agent [34].

With the rising number of literature available, it has also been indicated that such species may also exert cytotoxic effects, opening the possibility of its use in oncological therapies. According to Verma and Kumar [33], the chemopreventive properties of $W$. somnifera make it a potentially useful adjunct for patients undergoing radiation and chemotherapy. $W$. somnifera stimulates the immune system by stimulating the production of $\mathrm{T}$ lymphocytes and macrophages [35, 36], while Ziauddin et al. [37] stated a general increase in the number of white blood cells after administration of a root extract. W. somnifera application has also 


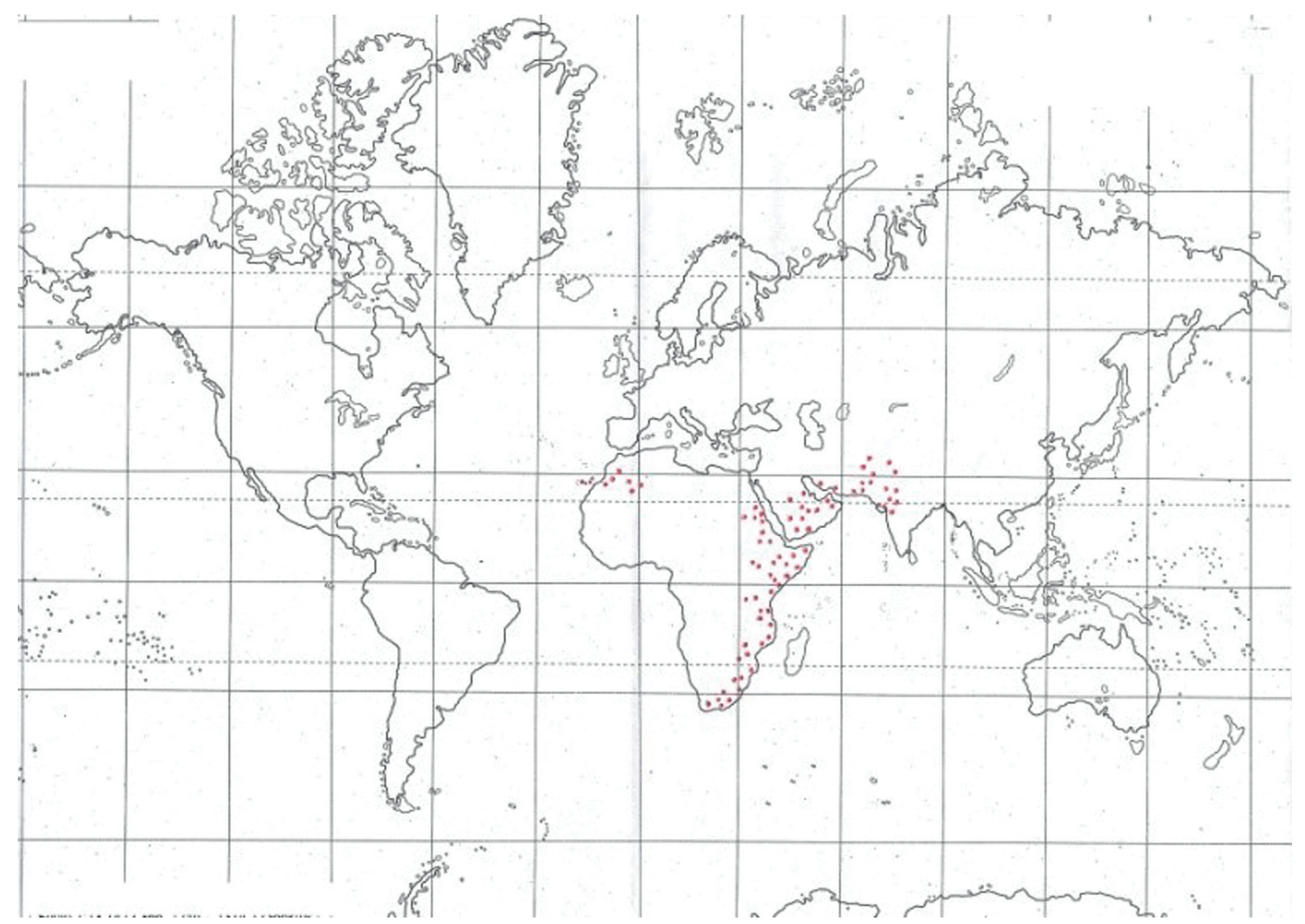

FIgURE 1: Red spots indicate the geographical distribution of Withania spp.

been shown to be able to reduce the number of skin lesions relative to the control group and showed inhibition of cancer cell growth in breast, lung, and colon cancer, which, apart from its cytotoxic abilities, is linked to their excellent antioxidant effects [38, 39]. Other authors, namely, Panda and Kar [40] and Andallu and Radhika [41], also stated an increase in T4 thyroid hormone concentration following $W$. somnifera root powder application, so that its use may be helpful in controlling the levels of hormones in diseases linked to hypothyroidism. Some authors have also indicated that $W$. somnifera root may be used for preventing cardiovascular disease, such as atherosclerosis [40-42]. For instance, in a human trial, a significant decrease in blood glucose and cholesterol levels to the extent of $10 \%$ and $12 \%$, respectively, was observed when compared to the group that received the conventional oral drug for type 2 diabetes (Daonil). These therapeutic effects could be due to one or more active principles in the roots of the plant. The hypoglycemic effect of $W$. somnifera root could be specifically attributed to its ability to enhance serum insulin levels and/ or the antioxidant activities of catalase, superoxide dismutase, and glutathione peroxidase [40-42].

\section{Phytoconstituents}

Chemical analysis of different plant parts of $W$. somnifera has afforded numerous compounds belonging to various chemical classes. The biologically active chemical constituents of $W$. somnifera are alkaloids (isopelletierine, anaferine), steroidal lactones (withanolides, withaferins), saponins containing an additional acyl group (sitoindoside VII and VIII), and withanolides with glucose at carbon 27 (sitoindoside XI and X). Among them, withanolides (steroidal lactones) have been used in an increasing number of drug formulations, given their promissory therapeutic abilities [43].

Despite being widely reported by a plethora of studies, Table 1 and Figure 2 present some of the most important withanolides isolated from Withania spp., considering its abundance and bioactive effects and representative structures, respectively. Misra et al. [44] reported withanolide A, withanolide $\mathrm{B}, 27$-hydroxy withanolide $\mathrm{B}$, withanolide $\mathrm{D}$, withaferin A, $16 \beta$-acetoxy- $6 \alpha, 7 \alpha$-epoxy- $5 \alpha$-hydroxy-1-oxowitha-

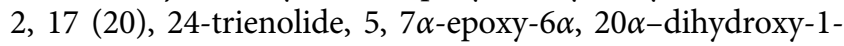
oxowitha-2, 24- dienolide along with common steroids, $\beta$-sitosterol and sitosterol, and their glucosides in W. somnifera. Matsuda et al. [45] isolated 7 new withanolide glycosides from $W$. somnifera roots, named withanoside I to VII, among which class VI is more abundant. Similarly, Bessalle and Lavie [46] isolated two chlorinated withanolides, namely, withanolide $\mathrm{C}$ and 4-deoxyphysalolactone from dried leaves of $W$. somnifera (Table 1).

There have been also reports on other constituents from plants of the Withania genus, namely, fatty acids and volatile compounds. Misra et al. [57] have reported new ergosterol and 1,4-dioxane derivatives along with various fatty acids 
TABle 1: List of selected withanolides and other compounds identified from Withania somnifera (L.) Dunal.

\begin{tabular}{|c|c|c|}
\hline $\begin{array}{l}\text { Plant } \\
\text { parts }\end{array}$ & Compounds & References \\
\hline \multirow{8}{*}{ Roots } & $\begin{array}{l}\text { Withanolide } \mathrm{A} \text {, withanolide } \mathrm{B}, 27 \text {-hydroxy withanolide } \mathrm{B} \text {, withanolide } \mathrm{D} \text {, withaferin } \mathrm{A}, 16 \beta \text {-acetoxy- } 6 \alpha, 7 \alpha \text {-epoxy- } \\
5 \alpha \text {-hydroxy-1-oxowitha- } 2,17 \text { (20), } 24 \text {-trienolide, } 5,7 \alpha \text {-epoxy- } 6 \alpha, 20 \alpha \text {-dihydroxy-1-oxowitha- } 2 \text {, } 24 \text {-dienolide }\end{array}$ & {$[44]$} \\
\hline & $\begin{array}{c}\text { Withanoside I, withanoside II, withanoside III, withanoside IV, withanoside V, withanoside VI, withanoside VII, } \\
\text { withaferin A, physagulin D, coagulin Q }\end{array}$ & [45] \\
\hline & Withasilolide $\mathrm{A}$, withasilolide $\mathrm{B}$, withasilolide $\mathrm{C}$, withasilolide $\mathrm{D}$, withasilolide $\mathrm{E}$, withasilolide $\mathrm{F}$ & [47] \\
\hline & $\begin{array}{c}\text { Withanolide } \mathrm{E} \text {, withanolide } \mathrm{F} \text {, withanolide } \mathrm{G} \text {, withanolide } \mathrm{H} \text {, withanolide } \mathrm{I} \text {, withanolide } \mathrm{J} \text {, withanolide } \mathrm{K} \text {, } \\
\text { withanolide } \mathrm{L} \text {, withanolide } \mathrm{M}\end{array}$ & [48] \\
\hline & Withanolide Q, withanolide R & [49] \\
\hline & Withanolide E, withanolide $\mathrm{F}$, withanolide S, withanolide P & [48] \\
\hline & Withanolide $\mathrm{T}$, withanolide $\mathrm{U}$ & [50] \\
\hline & Glucosomniferanolide & [51] \\
\hline Stem bark & Withasomnilide, withasomniferanolide, somniferanolide, somniferawithanolide, somniwithanolide & [52] \\
\hline \multirow{4}{*}{ Leaves } & Withanolide C, 4-deoxyphysalolactone & [46] \\
\hline & 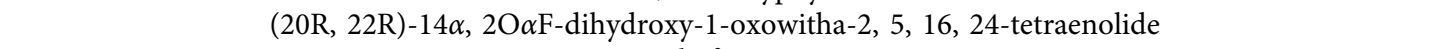 & [53] \\
\hline & Withaferin A & [54] \\
\hline & $\begin{array}{l}\text { 24,25-Dihydrowithanolide A, withanolide A, withanone, withaferin A, 27-hydroxy withanone, and } 17 \text {-hydroxy } \\
\text { withaferin A, 27-deoxy-16-en-withaferin A, 2, 3-dihydro-3 } \beta \text {-hydroxywithanone, } 2,3 \text {-dihydro withanone-3 } \beta \text {-O- } \\
\text { sulfate }\end{array}$ & [55] \\
\hline Fruits & $\begin{array}{l}\text { 24,25-Dihydrowithanolide VI, withanoside IV, withanoside } \mathrm{V} \text {, withanoside VI, withanamide A, withanamide } \mathrm{B} \text {, } \\
\text { withanamide } \mathrm{C} \text {, withanamide } \mathrm{D} \text {, withanamide } \mathrm{E} \text {, withanamide } \mathrm{F} \text {, withanamide } \mathrm{G} \text {, withanamide } \mathrm{H} \text {, withanamide I }\end{array}$ & [56] \\
\hline
\end{tabular}

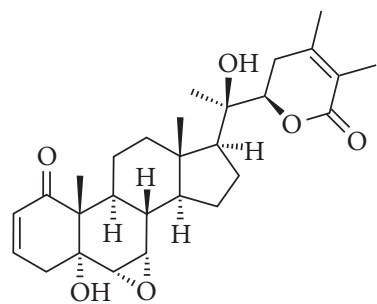

withanolide A

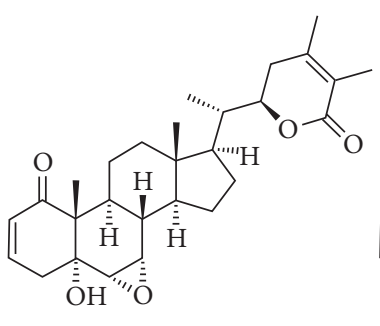

withanolide B

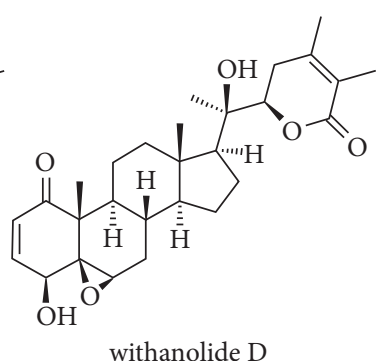

withanolide D

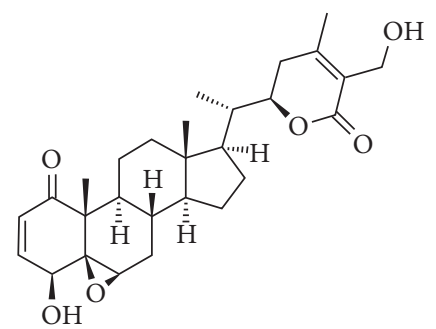

withaferin A

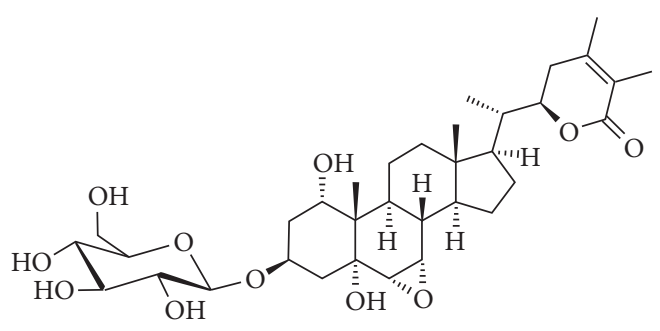

withanoside I

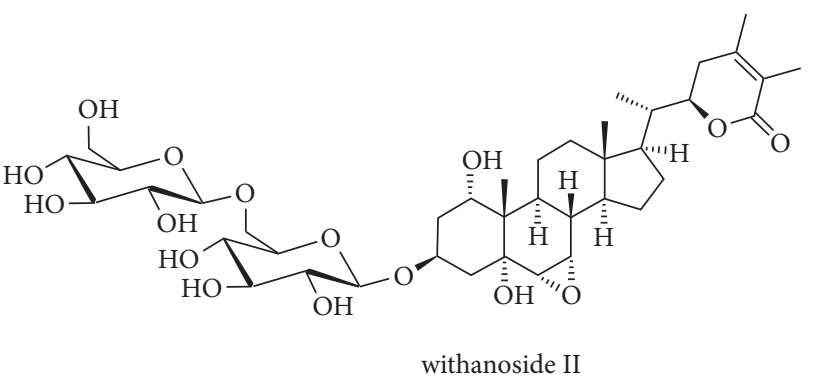

FIGURE 2: Chemical structures of some withanolide derivatives isolated from Withania somnifera.

(octacosane, oleic and stearic fatty acids), steroids, and oleanolic acid from W. somnifera roots. For example, Rautela et al. [58] studied the constituents of both ethanol and methanol extracts of $W$. somnifera leaves and roots and analyzed components by gas chromatography-mass spectrometry (GC-MS). Various compounds, including withanolide B, rosifoliol, and phytol, were reported [58]. Gulati et al. [59] studied the chemical composition of various extracts from $W$. somnifera roots of different genotypes and stated several metals in its composition, along with different concentrations of total sugars, alkaloids, and tannins. Bhatia et al. [60], studying the effect of chemotype variations in the chemical composition of $W$. somnifera fruits using GC-MS and nuclear magnetic resonance (NMR) spectroscopy, stated clear variations in metabolites contents in different chemotypes.

\section{Biological Activities}

Given the wide range of Withania species applications in Ayurvedic medicine for multiple aims, an increasing number of studies have progressively addressed their biological effects (Figure 3). Furthermore, with the popularization, the use of this plant as a food supplement in the market is also increasing. Indeed, both extracts and compounds isolated from the Withania species exhibit excellent 


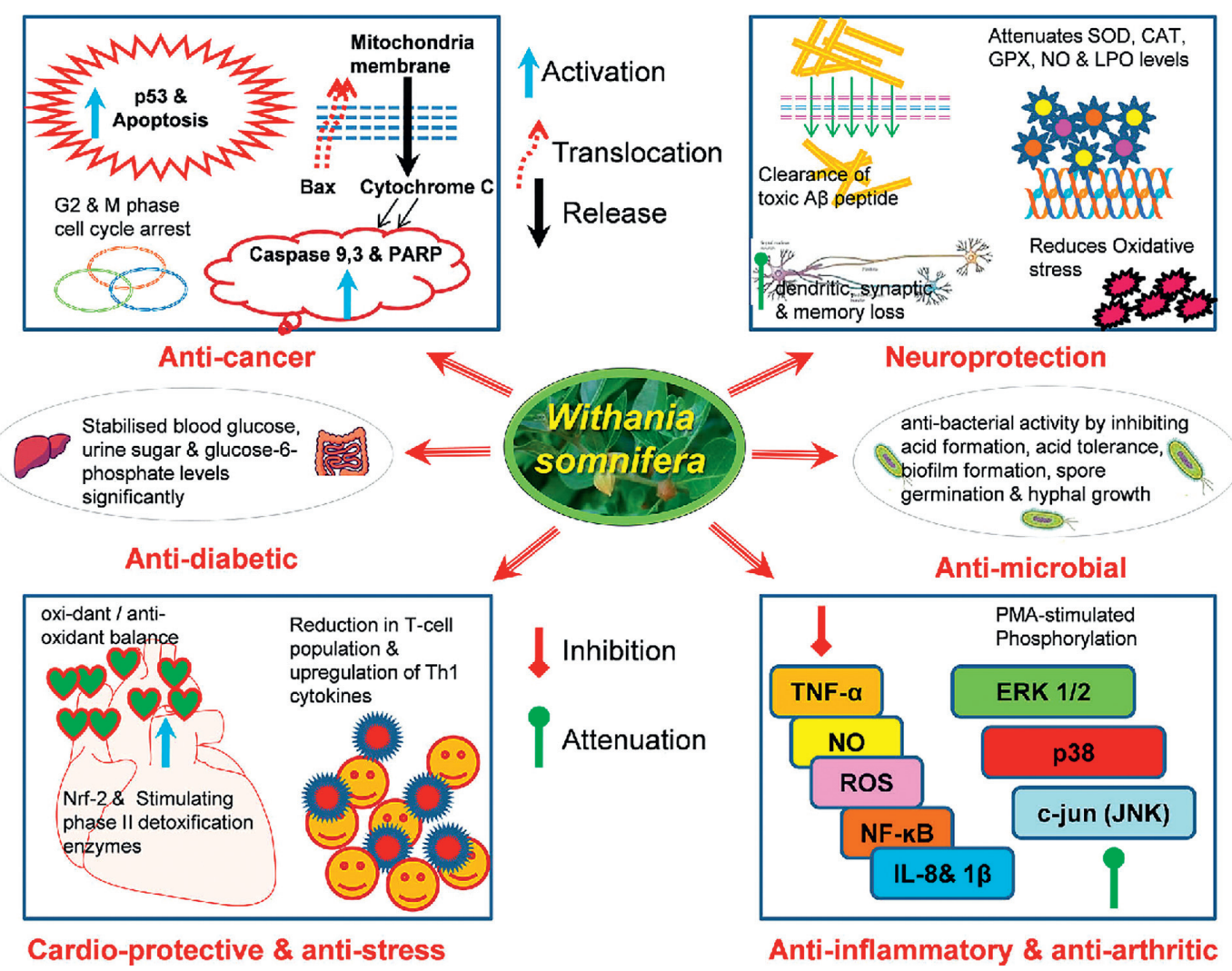

Figure 3: Major biological activities of Withania somnifera. Anticancer effects: W. somnifera exerts anticancer effects via multiple pathways, including nuclear factor (NFK-beta) and signal transducer and activator of transcription 3 (STAT3) signaling, PI3K (phosphoinositide 3kinase)/AKT (a serine-threonine protein kinase) and mitogen-activated protein kinase (MAPK) signaling, angiogenesis inhibition, oxidative stress induction, and p53 signaling. Melanoma cells were destroyed by withaferin A via ROS-mediated apoptosis. This process activated the mitochondrial pathway, resulting in the downregulation of $\mathrm{Bcl}-2$, translocation of Bax to the mitochondrial membrane, release of cytochrome $\mathrm{c}$ into the cytosol, abolition of transmembrane potential, and concomitant activation of caspases 9 and 3, resulting in the downregulation of proapoptotic protein, poly (ADP-Ribose) polymerase-1 (Parp-1) and DNA fragmentation. Neuroprotection: Withania somnifera reduced blood glucose, tissue lipid peroxidation (LPO), and glutathione (GSH) levels while increasing the activities of antioxidant enzymes such as glutathione peroxidase (GPx), glutathione reductase (GR), glutathione-S-transferase (GST), superoxide dismutase (SOD), and catalase (CAT). This demonstrates $W$. somnifera's significant free radical scavenging activity, as well as its ability to improve nonenzymatic and enzymatic antioxidants. W. somnifera root extract and withanolide A protected isolated hippocampus cells against hypobaric hypoxia-induced memory loss and neurodegeneration in vitro by stimulating the glutathione production pathway and decreasing glutathione (GSH) concentration. Furthermore, in cortical neurons treated with amyloid beta peptide, Withanolide A promoted both axonal and dendritic change as well as synaptic repair. Antidiabetic effects: $W$. somnifera leaf and root extracts showed antidiabetic activity by normalizing glucose uptake in skeletal myotubes and adipocytes in a dose-dependent manner. Furthermore, it considerably attenuated levels of urine and blood glucose, glucose 6-phosphatase, and tissue glycogen levels through nonenzymatic and enzymatic antioxidant mechanisms. Antimicrobial effects: the antimicrobial effect of Withania somnifera is attributed by inhibiting acid formation, acid tolerance, biofilm formation, spore germination, and hyphae growth, which in turn is mediated through gene silencing, immunopotentiation and cytotoxicity. Cardioprotective and antistress effects: the cardioprotective and cardiotropic properties of $W$. somnifera are demonstrated via nuclear factor erythroid 2-related transcription factor (Nrf)-2 and by activating phase II detoxification enzymes and abrogating apoptosis. Moreover, it is capable of alleviating chronic stress induced reduction of T-cell population and upregulated Th1 cytokines, thereby ensuring better stress endurance in animals as well as humans. Anti-inflammatory and antiarthritic effects: Withania somnifera alleviated inflammation by suppressing cytokines such as interleukin- (IL-) 8 and 1, tumor necrosis factor- (TNF-) $\alpha$, nitric oxide (NO), and reactive oxygen species (ROS). Furthermore, withaferin A, one of the active ingredients of $W$. somnifera, inhibited the expression of cell adhesion molecules, leukocyte adhesion and migration, IL-6 and TNF-a production, and NF-k activation (nuclear factor kappa-light-chain-enhancer of activated B cells). Furthermore, it inhibited the phosphorylation of p38, extracellular regulated kinases (ERK 12), and c-Jun N-terminal kinase by phorbol-12-myristate-13-acetate (PMA) (JNK).

biological activities, including antioxidant, antimicrobial, anti-inflammatory, and chemopreventive abilities, as assessed by both in vitro and in vivo studies. Concerning its in vitro biological effects, studies performed so far generally focused on their antioxidant activity and total phenolic content (spectrophotometric and/or chromatographic analyses) [61-68] and antimicrobial effects (disc diffusion assay and/or minimum inhibitory concentration (MIC)) $[65,69-81]$. In addition to in vitro studies, there has been a significant number of in vivo studies addressing the antiproliferative, cytotoxic, and anti-inflammatory effects of W. somnifera extracts in animal models [62]. 
5.1. Antioxidant Activity. The biological effects, and particularly the antioxidant potential and phytochemical constituents of W. somnifera, along with the other plants of the Withania genus, vary depending on the extraction method [61]. Methanol-chloroform-water $(1: 1: 1)$ extract of $W$. somnifera roots, with the highest content of all phytochemical constituents except tannins, had higher antioxidant and reducing activities when compared to water, acetone, and aqueous methanol $(1: 1)$ extracts (i,e. total antioxidant capacity of methanol-chloroform-water $(1: 1: 1)$ was $83.354 \pm 1.828$, aqueous methanol $(1: 1)$ was $76.978 \pm 2.210$, and water was $68.439 \pm 1.000$ ) [62]. Alkaloid content was found to be a leading contributor to the overall antioxidant and reducing activities of the extracts, closely followed by flavonoids and withanolides. Moreover, different parts of the plant may have different levels of antioxidant capacity [62]. For instance, Sumathi and Padma [82] reported that the leaves and fresh and dry tubers of $W$. somnifera had high contents in antioxidant compounds, while those present in tender roots and stems were not so high. Similar findings were also stated in other studies [63-65], with Alam et al. [66] also reporting that W. somnifera presents a good antioxidant activity, with catechin being the major polyphenol present in the highest concentration (13.01 \pm 8.93 to $30.61 \pm 11.41 \mathrm{mg} / \mathrm{g}$ ). High concentrations of polyphenols (gallic, syringic, benzoic, p-coumaric, and vanillic acids as well as catechin, kaempferol, and naringenin), flavonoids, and DPPH (1, 1-diphenyl-2-picrylhydrazyl) radical scavenging activities were detected in $80 \%$ methanolic extracts of $W$. somnifera fruits, roots, and leaves, ranging from $17.80 \pm 5.80$ to $32.58 \pm 3.16 \mathrm{mg} / \mathrm{g}$ (dry weight), $15.49 \pm 1.02$ to $31.58 \pm 5.07 \mathrm{mg} / \mathrm{g}$, and $59.16 \pm 1.20$ to $91.84 \pm 0.38 \mathrm{mg} / \mathrm{g}$, respectively [66]. Other authors also reported that $W$. somnifera root extract $(0.7$ and $1.4 \mathrm{mg} / \mathrm{kg}$ daily by gastric intubation method for 20 days) improves oxidative damage due to lead intoxication in mice by significantly decreasing lipid peroxidation and significantly increasing superoxide dismutase and catalase enzyme activities [67]. Free radical scavenging activity (FRSA) and metabolic profile of in vitro cultivated and fieldgrown Withania somnifera roots were examined by Samir et al. [68]. In vitro produced roots had significantly higher levels of FRSA, total phenolic content (TPC), and total flavonoid content (TFC) than field-grown samples. Furthermore, as compared to 45 -day-cultured samples, 30 day-cultured in vitro root samples had considerably greater FRSA, TPC, and TFC. Gas chromatography-mass spectrometry study detected a total of 29 compounds in in vitro cultivated and field-grown roots. Alcohols, organic acids, purine, pyrimidine, sugars, and putrescine were among the metabolites identified. Vanillic acid was found only in in vitro cultured root samples, and it was found in higher concentrations in 30 day-cultured in vitro root samples than in 45 day-cultured samples. As a result, 30 daycultured in vitro root samples are recommended as a substitute for field-grown roots in the development of medicinal and functional food products.

5.2. Anticancer, Anti-Inflammatory, and Cytotoxic Activity. Regarding the anticancer and cytotoxic effects of Withania species, Samir et al. [68] reported that ethanol extracts of aerial parts of $W$. somnifera demonstrated cytotoxic activity against human liver (HEPG-2) and breast (MCF-7) cell lines with halfmaximal inhibitory concentration $\left(\mathrm{IC}_{50}\right)$ of $8.5 \mu \mathrm{g} / \mathrm{mL}$ and $9.4 \mu \mathrm{g} / \mathrm{mL}$ for HEPG-2 and MCF-7, respectively. Cytotoxic activity of $W$. somnifera extracts was found to be at the stage of the G2/M phase and sub-G0 by arresting the cell cycle. Similarly, Naidoo et al. [83] reported that W. somnifera root extract effectively regulates the levels of the inflammatory cytokines while inhibiting the cancer cells' growth. Closely linked to the antioxidant activity, the cytotoxic activity of $W$. somnifera leaf extract against hepatocellular carcinoma cell line was also reported by Ahmed et al. [84]. In another study, it was observed that hydroalcoholic extract of $W$. somnifera root exhibited chemopreventive activity in mice with skin cancer [39] and fibrosarcoma [85]. Similarly, Padmavathi et al. [86] reported that $W$. somnifera root exerts chemopreventive effects against forestomach and skin carcinogenesis in mice.

On the other hand, closely linked to both antioxidant and anti-inflammatory effects, Khadrawy et al. [87] reported that $W$. somnifera demonstrated excellent effects against aluminum chloride $\left(\mathrm{AlCl}_{3}\right)$-induced neurotoxicity in rats. Aluminum increased lipid peroxidation and nitric oxide levels in the cortex, hippocampus, and striatum while lowering glutathione levels in the hippocampus and striatum. Lipid peroxidation, nitric oxide, and reduced glutathione levels were not significantly different in rats protected with $W$. somnifera extract. Furthermore, it inhibited the increased activity of acetylcholinesterase and $\mathrm{Na}^{+}, \mathrm{K}^{+}$, ATPase in the cortex, hippocampus, and striatum caused by $\mathrm{AlCl}_{3}$, apart from preventing a significant increase in tumor necrosis factor- $\alpha$ induced by $\mathrm{AlCl}_{3}$ in the cortex and hippocampus. These findings imply that $W$. somnifera extract can protect against aluminum neurotoxicity by acting as an antioxidant and anti-inflammatory agent. Furthermore, it helps to prevent the decline in cholinergic activity by maintaining normal acetylcholinesterase activity. The latter effect may support the use of $W$. somnifera as a memory booster. Also, Pingali et al. [88] reported that withaferin A of $W$. somnifera can cause type II collagen expression and increase reactive oxygen species and cyclooxygenase- 2 expression in rabbit articular chondrocytes depending on dose and time.

5.3. Cardioprotective Activity. Udayakumar et al. [89] suggested that the flavonoids and phenolics present in both root and leaf extracts of $W$. somnifera can be effective in reducing the blood glucose levels in diabetic rats. It was also reported that $W$. somnifera was effective in decreasing hyperlipidemia and oxidative stress in type 2 diabetic rats. When $W$. somnifera was given orally to type 2 diabetic rats at dosages $200 \mathrm{mg} / \mathrm{kg}$ and $400 \mathrm{mg} / \mathrm{kg}$, it led to significantly reduced serum levels of total cholesterol, triglyceride, lowdensity lipoprotein-cholesterol, and very-low-density lipoprotein-cholesterol while high-density lipoprotein-cholesterol levels increased significantly when compared to the diabetic control group [90]. Moreover, Udayakumar et al. [89] claimed that phenolic contents of the extracts of $W$. somnifera leaf and root were helpful in decreasing blood 
glucose levels in diabetic rats. Elkady and Mohamed [91] also reported that $W$. somnifera can be effective in protecting the occurrence of cardiotoxic effects induced by $\gamma$-rays in rats. A similar finding was also reported by Hosny Mansour and Farouk Hafez [92] that W. somnifera reduced hepatotoxicity in rats exposed to $\gamma$-radiation by significantly lowering serum hepatic enzymes, hepatic nitrate/nitrite, and malondialdehyde levels, significantly increasing antioxidant activity, and significant heme oxygenase (HO-1) induction. HO-1 enzymes protect the cell from injury due to oxidative and pathological stress, having a central role in cardiovascular protection [93].

5.4. Antimicrobial Activity. The antimicrobial activity of the Withania species is also remarkable. For example, methanol extracts of $W$. somnifera roots, fruits, and leaves have been revealed to be highly effective against gram-negative bacteria, including Klebsiella pneumoniae, Citrobacter freundii, Salmonella typhi, Pseudomonas aeruginosa, and Escherichia coli, as shown by Alam et al. [65]. Modulation of physiological functions of gut microbiota is involved in the mode of action of Withania somnifera root extracts. Similarly, the dichloromethane and ethyl acetate extracts of aerial parts of $W$. somnifera also evidenced excellent effects against Staphylococcus aureus and methicillin-resistant Staphylococcus aureus by disc diffusion assay, as shown by Mwitari et al. [69] and Hussain et al. [94].

The antimicrobial activity depends on the extraction method where ethanolic and methanolic extracts of $W$. somnifera root did not exhibit antibacterial activity against $K$. pneumoniae and methicillin-resistant $S$. aureus, whereas these microorganisms were inhibited by chloroform extracts of stem and leaves [70]. Moreover, the antimicrobial activities of different extracts of $W$. somnifera against different bacteria were reported by AbdEislam et al. [71]. The antibacterial activity of aqueous extract of $W$. somnifera against $E$. coli was higher compared to that of the alcoholic extract [72]. The extracts of $W$. somnifera root were also effective against multidrug-resistant $S$. aureus [73], with methanol extract of $W$. somnifera being also effective in inhibiting oral bacteria, like Streptococcus mutans and Streptococcus sobrinus [74]. Halamova et al. [75] investigated the antimicrobial activity of $W$. somnifera against human pathogenic bacteria and observed that those pathogens were more susceptible to extracts compared to beneficial Bifidobacteria. Interestingly, Zahran et al. [95] also reported that the dietary supplementation with $W$. somnifera root powder exhibited immunotherapeutic activity against Aeromonas hydrophila in Nile tilapia.

When looking at the effect of $W$. somnifera isolated constituents, flavonoids have shown excellent antimicrobial effects against C. albicans, S. aureus, Proteus mirabilis, E. coli, and $P$. aeruginosa, although no effects were noted against Aspergillus flavus or Aspergillus niger [76]. Interestingly, the minimum inhibitory concentration (MIC) of W. somnifera methanol extract against $C$. albicans and Neisseria gonorrhoeaewas reported as $20 \mathrm{mg} / \mathrm{mL}$ and $0.5 \mathrm{mg} / \mathrm{mL}$, while that of water extract against $N$. gonorrhoeaewas $10 \mathrm{mg} / \mathrm{mL}$ [77]. In addition, $W$. somnifera glycoprotein revealed antibacterial effects against Clavibacter michiganensis subsp. michiganensis and antifungal activity against A. flavus, Fusarium oxysporum, and Fusarium verticillioides [78]. Also, it was reported that $W$. somnifera can be utilized in the synthesis of silver nanoparticles with excellent antioxidant, antimicrobial, and anticancer potential [79-81].

\section{Health-Promoting Effects}

As previously mentioned, Withania has been used since a long time ago for different clinical purposes. In the traditional system of medicine, Withania somnifera has been used for anti-inflammatory, anticancer, antioxidant, adaptogenic, and antistress purposes, along with as an immunomodulator. Moreover, it also exerts a positive influence on endocrine, cardiorespiratory, and central nervous system (CNS) levels. For instance, it was stated that $W$. somnifera is a powerful help in cancer management, with good tolerance [96]. Recently, upon evaluating the clinical evidence base and investigating the potential role of $W$. somnifera in managing cognitive dysfunction, $\mathrm{Ng}$ et al. [97] found that $W$. somnifera extract improved performance on cognitive tasks, executive function, attention, and reaction time. It also appears to be well tolerated, with good adherence and minimal side effects. Using standardized $W$. somnifera extracts or its bioactive ingredients, new and more effective medications to treat cognitive impairment could be produced [97]. Notwithstanding, despite the broad spectrum of preclinical data available, the number of clinical trials performed using $W$. somnifera is markedly scarcer (Table 2).

\section{Food-Pharma Industry: Safety and Adverse Effects}

W. somnifera has traditionally been available in the form of capsules and powder, being most often sold as a supplement. However, it can now be found in a variety of food products, including ghee, honey, and kombucha. More recently, $W$. somnifera has also been incorporated in baked goods, juices, and beverages, respectively, sweets (candies/snacks), and dairy products marketed as "Functional Foods" or "Nutraceuticals." The worth of note is that the amount of $W$. somnifera in food can vary widely, where the addition of powder can range from 1 to $10 \%$ depending on the product (baked good vs. beverage). Also, levels of W. somnifera up to $5 \%$ have also been found to have acceptable sensorial features [114].

Herbal cookies designed as functional foods have also been developed with $W$. somnifera leaf powder, with the final product presenting with an acceptable color, taste, and texture while maintaining an acceptable shelf-life [115]. Incorporating $W$. somnifera into foods can serve several functions; for example, it can provide excellent antioxidant and human health benefits. Moreover, the addition of $W$. somnifera to ghee (clarified butter fat) was found to be an effective natural antioxidant to prevent oxidative degradation (less than synthetic antioxidant BHA, butylated hydroxyanisole) apart from providing health-promoting benefits. The antioxidant activities evaluated were 
TABLE 2: Health-promoting effect of Withania somnifera.

\begin{tabular}{|c|c|c|c|c|}
\hline Biological activity & Dose/duration & Study design/subjects & Effect & References \\
\hline \multirow{7}{*}{$\begin{array}{l}\text { Antistress and } \\
\text { antianxiety }\end{array}$} & $\begin{array}{l}500 \mathrm{mg} \text { dried aqueous } \\
\text { extract of roots and } \\
\text { leaves/twice a day for } 14\end{array}$ & $\begin{array}{l}\text { Double-blind, placebo-controlled, } \\
\text { randomized, crossover study }(n=20 \\
\text { healthy men) }\end{array}$ & Decrease aortic pressure & [88] \\
\hline & $\begin{array}{l}300 \mathrm{mg} \text { roots extract/day, } \\
45 \text { days }\end{array}$ & $\begin{array}{l}\text { Prospective double-blind, randomized, } \\
\text { placebo-controlled trial ( } n=64 \text { subjects } \\
\text { with a history of chronic stress) }\end{array}$ & $\begin{array}{l}\text { Reduce cortisol levels and the } \\
\text { scores of stress-assessment scales }\end{array}$ & [98] \\
\hline & $\begin{array}{c}500 \text { mg powder capsule/ } \\
\text { twice a day, twice a day, } 30 \\
\text { days }\end{array}$ & $\begin{array}{l}\text { Single-trial group ( } n=30 \text { subjects with } \\
\text { generalized weakness) }\end{array}$ & $\begin{array}{l}\text { Reduce fatigue symptoms, } \\
\text { improve workability and quality- } \\
\text { of-life dimension scores }\end{array}$ & [99] \\
\hline & $\begin{array}{l}120 \mathrm{mg} \text { root extract/day, } \\
\text { six weeks }\end{array}$ & $\begin{array}{l}\text { Double-blind placebo-controlled trial } \\
\text { ( } n=30 \text { individuals with the obsessive- } \\
\text { compulsive disorder) }\end{array}$ & $\begin{array}{l}\text { Improve effect in Yale-Brown } \\
\text { obsessive-compulsive scale } \\
\text { (symptoms severity) }\end{array}$ & {$[100]$} \\
\hline & $\begin{array}{l}300 \mathrm{mg} \text { root extract/day } \\
12 \text { weeks }\end{array}$ & $\begin{array}{c}\text { Clinical control-placebo trial }(n=55 \\
\text { type II diabetics, under oral } \\
\text { hypoglycemics) }\end{array}$ & $\begin{array}{l}\text { Improvement in stress and } \\
\text { complaints }\end{array}$ & {$[101]$} \\
\hline & $\begin{array}{l}250 \mathrm{mg} \text { root ethanol } \\
\text { extract/twice a day, } 6 \\
\text { weeks }\end{array}$ & $\begin{array}{l}\text { Double-blind, placebo-controlled } \\
\text { study ( } n=39 \text { subjects with generalized } \\
\text { anxiety disorder, mixed anxiety and } \\
\text { depression, panic disorder, and } \\
\text { adjustment disorder with anxiety) }\end{array}$ & $\begin{array}{l}\text { Improvement in anxiety score } \\
\text { across time }\end{array}$ & {$[102]$} \\
\hline & $\begin{array}{l}1000 \mathrm{mg} \text { standardized } \\
\text { root extract/day, } 12 \text { weeks }\end{array}$ & $\begin{array}{l}\text { Randomized, placebo-controlled, } \\
\text { double-blind ( } n=66 \text { patients with } \\
\text { depression and anxiety symptoms) }\end{array}$ & $\begin{array}{l}\text { Improvement in depression } \\
\text { single-item and anxiety- } \\
\text { depression cluster scores and } \\
\text { anxiety symptoms }\end{array}$ & [103] \\
\hline \multirow{3}{*}{ Cognitive } & $\begin{array}{l}500 \text { mg standardized root } \\
\text { extract/day } 8 \text { weeks }\end{array}$ & $\begin{array}{c}\text { Randomized placebo-controlled } \\
(n=53 \text { patients with bipolar disorder })\end{array}$ & $\begin{array}{l}\text { Improvement in auditory-verbal } \\
\text { working memory (digit span } \\
\text { backward) }\end{array}$ & {$[104]$} \\
\hline & $\begin{array}{l}250 \mathrm{mg} \text { dried aqueous } \\
\text { extract of roots and } \\
\text { leaves/twice daily, } 14 \text { days }\end{array}$ & $\begin{array}{l}\text { Prospective, double-blind, placebo- } \\
\text { controlled, crossover }(n=20 \text { healthy } \\
\text { men) }\end{array}$ & $\begin{array}{l}\text { Improvement in the cognitive and } \\
\text { psychomotor performance }\end{array}$ & {$[105]$} \\
\hline & $\begin{array}{l}300 \mathrm{mg} \text { root extract/twice } \\
\text { daily, } 8 \text { weeks }\end{array}$ & $\begin{array}{l}\text { Prospective, randomized, double- } \\
\text { blind, placebo-controlled ( } n=50 \\
\text { healthy man and female adults) }\end{array}$ & $\begin{array}{l}\text { Improvement in general memory } \\
\text { and executive function }\end{array}$ & {$[106]$} \\
\hline \multirow{3}{*}{ Cardiorespiratory } & $\begin{array}{l}300 \mathrm{mg} \text { roots extract/ } \\
\text { twice daily, } 12 \text { weeks }\end{array}$ & $\begin{array}{l}\text { Randomized, double-blind, and } \\
\text { placebo-controlled ( } n=50 \text { healthy } \\
\text { athletic male and/or female adult) }\end{array}$ & $\begin{array}{l}\text { Enhances the cardiorespiratory } \\
\text { endurance, improvement in the } \\
\text { self-reported quality-of-life } \\
\text { questionnaire }\end{array}$ & {$[107]$} \\
\hline & $\begin{array}{l}250 \mathrm{mg} \text { standardized root } \\
\text { extract/twice daily, } 14 \\
\text { days }\end{array}$ & $\begin{array}{l}\text { Prospective, double-blind, } \\
\text { randomized, and placebo-controlled } \\
(n=50 \text { healthy men })\end{array}$ & $\begin{array}{l}\text { Increased velocity, power, and } \\
\text { maximum oxygen consumption }\end{array}$ & [108] \\
\hline & $\begin{array}{l}500 \mathrm{mg} \text { standardized root } \\
\text { extract/day Sensoril }{ }^{\circledR}, 12 \\
\text { weeks }\end{array}$ & $\begin{array}{l}\text { Randomized, double-blind, placebo- } \\
\text { controlled ( } n=40 \text { healthy, } \\
\text { recreationally active men) }\end{array}$ & $\begin{array}{l}\text { Improves upper- and lower-body } \\
\text { strength in active men }\end{array}$ & [109] \\
\hline \multirow{3}{*}{$\begin{array}{l}\text { Analgesic/anti- } \\
\text { inflammatory }\end{array}$} & $\begin{array}{l}1000 \mathrm{mg} \text { standardized } \\
\text { root extract/day, 10-14 } \\
\text { days }\end{array}$ & $\begin{array}{l}\text { Randomized placebo-controlled } \\
\qquad(n=26 \text { healthy men })\end{array}$ & $\begin{array}{l}\text { Increased mean pain threshold } \\
\text { time }\end{array}$ & {$[110]$} \\
\hline & $\begin{array}{l}250-125 \mathrm{mg} \text { standardized } \\
\text { root extract/twice daily, } \\
12 \text { weeks }\end{array}$ & $\begin{array}{l}\text { Randomized, double-blind placebo- } \\
\text { controlled ( } n=16 \text { patients with knee } \\
\text { joint pain and discomfort) }\end{array}$ & $\begin{array}{l}\text { Reduced pain and disability scores } \\
\text { (both doses), and promoted a } \\
\text { better response (at a higher dose) }\end{array}$ & {$[111]$} \\
\hline & $\begin{array}{l}450 \mathrm{mg} \text { root extract/day, } \\
15 \text { days }\end{array}$ & $\begin{array}{l}\text { Double-blind, placebo-controlled, } \\
\text { crossover ( } n=42 \text { patients with } \\
\text { osteoarthritis })\end{array}$ & $\begin{array}{l}\text { Reduced severity pain and a } \\
\text { disability score }\end{array}$ & {$[112]$} \\
\hline Chemoprotective & $\begin{array}{c}2000 \mathrm{mg} \text { root extract/day } \\
\text { every } 8 \mathrm{~h} \text { during } \\
\text { chemotherapy cycles }\end{array}$ & $\begin{array}{c}\text { Open-label prospective } \\
\text { nonrandomized comparative trial } \\
(n=100 \text { patients with breast cancer in } \\
\text { all stages })\end{array}$ & $\begin{array}{c}\text { Reduce score Piper's fatigue score } \\
\text { Reduced Schwartz's cancer fatigue } \\
\text { score and improved quality-of-life } \\
\text { questionnaire scores }\end{array}$ & [113] \\
\hline
\end{tabular}


$\beta$-carotene bleaching assay, DPPH assay, and Rancimat method, and the doses evaluated were $1.0 \%$ and $0.5 \%(\mathrm{w} / \mathrm{w})$ for aqueous and ethanolic $W$. somnifera extract, respectively. Perhaps not surprisingly, much food product development research has focused on incorporating $W$. somnifera into foods commonly consumed in India. Nonetheless, as foods containing $W$. somnifera are becoming widely available, increasing attention and consideration must be given to the potential occurrence of adverse effect(s) as a result of overingestion [116].

7.1. From Therapeutic to Safety Profile. Animal and human studies have been conducted to determine the potential impact in the treatment of a wide range of diseases, including but not limited to cancer, immunosuppressive diseases, anxiety and depression, Parkinson's disease (PD), and fertility [117]. Studies performed so far suggest that the consumption of up to $100 \mathrm{mg}$ per $\mathrm{kg}$ of body weight in a single dosage or approximately $21 \mathrm{~g}$ per day is safe. Typically, a therapeutic dose is $\leq 10 \mathrm{~g} / \mathrm{day}$, so that a total intake can be more closely controlled when consumed in a capsule form. In an animal model, $W$. somnifera extract was given for 28 days at oral doses of $0,500,1000$, and $2000 \mathrm{mg} / \mathrm{kg}$ body weight, and data obtained suggest that the administration of $W$. somnifera extract up to $2000 \mathrm{mg} / \mathrm{kg} /$ day did not trigger adverse effect [118].

Several review articles broadly cover various human clinical trials suggesting that $W$. somnifera has no adverse health effects during long-term ( $\geq$ one-year) administration [119]. For example, a group of 64 subjects aged from 18 to 54 received a $300 \mathrm{mg}$ capsule of $W$. somnifera root extract for a period of 60 days [98]. Any incidences of adverse events were comparable in the placebo-control group and $W$. somnifera group, with the difference being not statistically significant. Another study investigated the use of $W$. somnifera in reproductive issues; for that, a group of 41 men received a dose of 4 tablets ( $500 \mathrm{mg}$ each) 3 times/day (i.e., $6 \mathrm{~g} /$ day) containing $W$. somnifera root powder through oral route after intake of food for 60 days [120]. The placebo (wheat powder) received a tablet form, consisting of 4 tablets (500 $\mathrm{mg}$ each) 3 times/day (i.e., $6 \mathrm{~g} /$ day) $(n=45)$. No adverse health effects were stated using the $W$. somnifera root powder.

The impact of $W$. somnifera root extract supplementation in muscle strength and recovery of 57 male subjects (18 to 50 years old) was also evaluated [121]. Subjects in the treatment group received $300 \mathrm{mg}$ of $W$. somnifera root extract twice daily for 8 weeks, and no adverse health events were reported. Taken together, data obtained so far appears to support that $W$. somnifera has no toxic effects; however, such studies were not specifically designed to address safety and adverse effects. Also, most studies were of short duration and, as such, may not be indicative of the long-term impact of W. somnifera intake in human health.

7.2. Pregnancy and Teratogenicity. To what concerns, the safe use of $W$. somnifera during pregnancy, whether as a supplement or in food, remains uncertain. Reports suggest that W. somnifera might have abortifacient properties during pregnancy, indicating classification under toxic plants that cause abortion and sterility $[122,123]$. In this way, some researchers addressed the concern by orally administering $W$. somnifera root extract to pregnant rats during a period of major organogenesis and histogenesis (days 5 to 19 of gestation). Briefly, pregnant rats received a dose of 500,1000 , and $2000 \mathrm{mg} / \mathrm{kg} /$ day and were monitored for a range of clinical symptoms, although no evidence of maternal or fetal toxicity was stated. The root extract provoked no changes in body weight of parental females, the number of corpora lutea, implantations, viable fetuses, and external, skeletal, and visceral malformations. Thus, the authors proposed evidence of safety related to $W$. somnifera root extract at least at $2000 \mathrm{mg} / \mathrm{kg} / \mathrm{day}$ [124]. Regardless, caution must be exercised concerning the use of $W$. somnifera during pregnancy given the limited number of published studies addressing the issue $[122,123]$. According to the National Institutes of Health [125], W. somnifera contains several compounds that may cause miscarriage, premature birth, or uterine contractions [124]. W. somnifera is commonly safely used by adults in doses up to $1000 \mathrm{mg}$ per day, for up to 12 weeks, but pregnant and breastfeeding women should not consume [125].

Collectively, the wealth of research suggests that oral intake of $W$. somnifera is safe with a possible exception during pregnancy. In addition, given that $W$. somnifera is being formulated into a wide range of commercially available food and beverages, the total day consumption by consumers of such products may need to be more closely considered. In this sense, future research may focus on differences in bioavailability of the various forms (leaf and root powder, extracts, and essential oils) related to safety and adverse effects.

\section{Conclusion}

The Withania genus has been traditionally used for its therapeutic potential in numerous diseases, of which insomnia, depression, and immunostimulant effects stand out. However, remarkable anti-inflammatory and rejuvenating activities have also been stated, with in vitro and in vivo studies highlighting excellent antioxidant, antiproliferative, cytotoxic, anti-inflammatory, and antimicrobial activity. However, not all species present the same activity, with the most studied and economically important one being the roots of $W$. somnifera. More importantly, the clinical studies performed so far have progressively affirmed the $W$. somnifera therapeutic effects, namely, its excellent ability to increase vitality, physical performance, and hematopoietic capacity and to treat insomnia. Moreover, $W$. somnifera is being valued for its ability to promote longevity and strengthen the immune system without stimulating the body's reserves. Nonetheless, despite the advances stated so far, further clinical trials and more precise and deeper studies, namely, addressing the bioavailability and effect of pure compounds and the occurrence of synergistic effects when used in combination, along with the development of methods to standardize the percentage composition of active compound(s) in marketed products, are the fields that most 
need to be intensively explored. Actually, although it is possible to find various products containing $W$. somnifera at variable amounts and safety studies do not report adverse effects, it is of utmost importance to have deeper knowledge on synergistic effects that may possibly occur with other food components and to know what are the effects when high doses are used and even what are the effects in pregnancy.

\section{Data Availability}

The data supporting this review are from previously reported studies and datasets, which have been cited. The processed data are available from the corresponding author upon request.

\section{Conflicts of Interest}

The authors declare that they have no conflicts of interest.

\section{Authors' Contributions}

All authors contributed equally to the manuscript. Conceptualization was done by Javad Sharifi-Rad, Hari Prasad Devkota, Beraat Özçelik, Miquel Martorell, William C. Cho, and Natália Cruz-Martins; Cristina Quispe, Seyed Abdulmajid Ayatollahi, Farzad Kobarfard, Mariola Staniak, Anna Stępień, Katarzyna Czopek, Surjit Sen, Krishnendu Acharya, Karl R. Matthews, Bilge Sener, Celale Kırkın, Montserrat Victoriano, Deepak Chandran, Manoj Kumar, and Hafiz Ansar Rasul Suleria contributed to validation, investigation, data curation, and writing the draft of the manuscript; review and editing of the manuscript were performed by Javad Sharifi-Rad, Hari Prasad Devkota, Beraat Özçelik, Miquel Martorell, William C. Cho, and Natália Cruz-Martins. All authors read and approved the final manuscript.

\section{Acknowledgments}

N. C. -M. acknowledges the Portuguese Foundation for Science and Technology under the Horizon 2020 Program (PTDC/PSI-GER/28076/2017).

\section{References}

[1] R. G. Olmstead, L. Bohs, H. A. Migid, E. Santiago-Valentin, V. F. Garcia, and S. M. Collier, "A molecular phylogeny of the Solanaceae," Taxon, vol. 57, no. 4, pp. 1159-1181, 2008.

[2] S. Singh and S. Kumar, Withania somnifera: The Indian Ginseng, Ashwagandha, Central Institute of Medical and Aromatic Plants, Lucknow, India, 1998.

[3] J. M. Wood, "List of flora of natal," Transactions of the South African Philosophical Society, vol. 18, p. 197, 1908.

[4] A. N. Gifri, "Studies in flora of yemen 2 new records for the flora aden," Candollea, vol. 47, pp. 613-619, 1992.

[5] A. Kumar, M. K. Kaul, M. K. Bhan, P. K. Khanna, and K. A. Suri, "Morphological and chemical variation in 25 collections of the indian medicinal plant, Withania somnifera (L.) dunal (Solanaceae)," Genetic Resources and Crop Evolution, vol. 54, no. 3, pp. 655-660, 2007.

[6] B. R. Rajeswara Rao, D. K. Rajput, G. Nagaraju, and G. Adinarayana, "Opportunities and challenges in the cultivation of ashwagandha Withania somnifera (L.) dunal," Journal of Pharmacognosy, vol. 3, pp. 88-91, 2012.

[7] R. Udayakumar, S. Kasthurirengan, T. S. Mariashibu et al., "Analysis of genetic variation among populations of Withania somnifera (L.) in South India based on RAPD markers," European Journal of Medicinal Plants, vol. 3, no. 2, pp. 266-280, 2013.

[8] M. S. Negi, V. Sabharwal, N. Wilson, and M. S. Lakshmikumaran, "Comparative analysis of the efficiency of SAMPL and AFLP in assessing genetic relationships among Withania somnifera genotypes," Current Science, vol. 91, pp. 464-471, 2006.

[9] B. A. Mir, A. Kumar, S. Koul, M. K. Kaul, S. N. Raina, and A. S. Soodan, "Assessment and characterization of genetic diversity in Withania somnifera (L.) Dunal using RAPD and AFLP markers," African Journal of Biotechnology, vol. 10, pp. 14746-14756, 2011.

[10] M. Umadevi, R. Rajeswari, C. Sharmila Rahale et al., "Traditional and medicinal uses of Withania somnifera," The Pharma Innovation, vol. 1, pp. 102-110, 2012.

[11] A. S. Saroya, Contemporary Phytomedicines, CRC Press, Boca Raton, FL, USA, 2017.

[12] B. A. Mir, J. Khazir, N. A. Mir, T. Hasan, and S. Koul, "Botanical, chemical and pharmacological review of Withania somnifera (Indian ginseng): an ayurvedic medicinal plant," Indian Journal of Drugs in Dermatology, vol. 1, pp. 147-160, 2012.

[13] S. L. Nayar, "Medicinal plants of commercial importance found wild in Uttar Pradesh and their distribution," JBNHS, vol. 61, pp. 651-661, 1964.

[14] R. Gupta, "Survey record of medicinal and aromatic plants of chamba forest division, himachal pradeash," The Indian Forester, vol. 90, pp. 454-468, 1964.

[15] D. B. Deb, "Enumeration, synonymy and distribution of the Solanaceae in India," Journal of Economic and Taxonomic Botany, vol. 1, pp. 33-54, 1980.

[16] K. B. Nigam, "Aswagandha cultivation," Indian Horticulture, vol. 28, pp. 39-41, 1894.

[17] S. K. Verma, A. Shaban, R. Purohit, M. L. Chimata, G. Rai, and O. P. Verma, "Immunomodulatory activity of Withania somnifera (L.)," Journal of Chemical and Pharmaceutical Research, vol. 4, pp. 559-561, 2012.

[18] S. S. Ahmad, "Medicinal wild plants from lahore-islamabad motorway (M-2)," Pakistan Journal of Botany, vol. 39, pp. 355-375, 2007.

[19] S. A. Gilani, A. Kikuchi, and K. N. Watanabe, "Genetic variation within and among fragmented populations of endangered medicinal plant, Withania coagulans (Solanaceae) from Pakistan and its implications for conservation," African Journal of Biotechnology, vol. 8, pp. 2948-2958, 2009.

[20] M. Mirjalili, E. Moyano, M. Bonfill, R. Cusido, and J. Palazón, "Steroidal lactones from Withania somnifera, an ancient plant for novel medicine," Molecules, vol. 14, no. 7, pp. 2373-2393, 2009.

[21] S. K. Meher, B. Das, P. Panda, G. C. Bhuyan, and M. M. Rao, "Uses of Withania somnifera (linn) dunal (ashwagandha) in ayurveda and its pharmacological evidences," Research Journal of Pharmacology and Pharmacodynamics, vol. 8, no. 1, pp. 23-29, 2016.

[22] A. Bano, N. Sharma, H. Dhaliwal, and V. Sharma, "A systematic and comprehensive review on Withania somnifera (L.) dunal- an Indian ginseng," British Journal of Pharmaceutical Research, vol. 7, no. 2, pp. 63-75, 2015. 
[23] C. H. Wright, Flora Capensis, Royal Botanic Gardens, Kew, UK, 1904.

[24] C. H. Wright, Flora of Tropical Africa, Royal Botanic Gardens, Kew, UK, 1905.

[25] C. K. Atal and A. E. Schwarting, "Ashwagandha-an ancient Indian drug," Economic Botany, vol. 15, no. 3, pp. 256-263, 1961.

[26] C. K. Atal, O. P. Gupta, K. Raghunathan, and K. L. Dhar, Pharmacognosy and Phytochemistry of Withania somnifera (Linn.) Dunal (Ashwagandha), Central Council for Research in Indian Medicine and Homeopathy, New Delhi, India, 1975.

[27] J. Edmonds, Flora Somalia, Royal Botanic Gardens, Kew, UK, 2006.

[28] Q. Uddin, L. Samiulla, V. K. Singh, and S. S. Jamil, "Phytochemical and pharmacological profile of Withania somnifera dunal: a review," JAPS, vol. 2, pp. 170-175, 2012.

[29] R. Asthana, M. K. Raina, R. Asthana, and M. K. Raina, "Pharmacology of Withania somnifera (L.) dunal-a review," Ind Drugs, vol. 26, 1989.

[30] A. K. Tripathi, Y. N. Sukla, and S. Kumar, "Ashwagandha [(Withania somnifera, dunal (Solanaceae)]: a status report," Journal of Medicinal and Aromatic Plant Sciences, vol. 8, pp. 46-62, 1996.

[31] A. Bhattacharya, S. Ghosal, and S. K. Bhattacharya, "Antioxidant effect of Withania somnifera glycowithanolides in chronic footshock stress-induced perturbations of oxidative free radical scavenging enzymes and lipid peroxidation in rat frontal cortex and striatum," Journal of Ethnopharmacology, vol. 74, no. 1, pp. 1-6, 2001.

[32] S. K. Bhattacharya and A. V. Muruganandam, "Adaptogenic activity of Withania somnifera: an experimental study using a rat model of chronic stress," Pharmacology Biochemistry and Behavior, vol. 75, no. 3, pp. 547-555, 2003.

[33] S. K. Verma and A. Kumar, "Therapeutc uses of Withania somnifera (Ashwagandha) with a note on withanolides and its pharmacological actions," Asian Journal of Pharmaceutical and Clinical Research, vol. 4, pp. 1-4, 2011.

[34] S. K. Kulkarni and A. Dhir, "Withania somnifera: an Indian ginseng," Progress in Neuro-Psychopharmacology and Biological Psychiatry, vol. 32, no. 5, pp. 1093-1105, 2008.

[35] G. Kuttan, "Use of Withania somnifera dunal as an adjuvant during radiation therapy," Indian Journal of Experimental Biology, vol. 34, pp. 854-856, 1996.

[36] T. Iuvone, G. Esposito, F. Capasso, and A. A. Izzo, "Induction of nitric oxide synthase expression by Withania somnifera in macrophages," Life Sciences, vol. 72, no. 14, pp. 1617-1625, 2003.

[37] M. Ziauddin, N. Phansalkar, P. Patki, S. Diwanay, and B. Patwardhan, "Studies on the immunomodulatory effects of Ashwagandha," Journal of Ethnopharmacology, vol. 50, no. 2, pp. 69-76, 1996.

[38] L. Davis and G. Kuttan, "Effect of Withania somnifera on CTL activity," Journal of Experimental \& Clinical Cancer Research: CR, vol. 21, pp. 115-118, 2002.

[39] J. Prakash, S. K. Gupta, and A. K. Dinda, "Withania somnifera root extract prevents DMBA-induced squamous cell carcinoma of skin in swiss albino mice," Nutrition and Cancer, vol. 42, no. 1, pp. 91-97, 2002.

[40] S. Panda and A. Kar, "Withania somnifera and Bauhinia purpurea in the regulation of circulating thyroid hormone concentrations in female mice," Journal of Ethnopharmacology, vol. 67, no. 2, pp. 233-239, 1999.

[41] B. Andallu and B. Radhika, "Hypoglycemic, diuretic and hypocholesterolemic effect of winter cherry (Withania somnifera, dunal) root," Indian Journal of Experimental Biology, vol. 38, pp. 607-609, 2000.

[42] S. Panda and A. Kar, "Changes in thyroid hormone concentrations after administration of ashwagandha root extract to adult male mice," Journal of Pharmacy and Pharmacology, vol. 50, no. 9, pp. 1065-1068, 2011.

[43] R. Jain and S. Kachhwaha, "Phytochemistry, pharmacology, and biotechnology of Withania somnifera and Withania coagulans: a review," Journal of Medicinal Plants Research, vol. 6, pp. 5388-5399, 2012.

[44] L. Misra, P. Mishra, A. Pandey, R. S. Sangwan, N. S. Sangwan, and R. Tuli, "Withanolides from Withania somnifera roots," Phytochemistry, vol. 69, no. 4, pp. 1000-1004, 2008.

[45] H. Matsuda, T. Murakami, A. Kishi, and M. Yoshikawa, "Structures of withanosides I, II, III, IV, V, VI, and VII, new withanolide glycosides, from the roots of Indian Withania somnifera DUNAL. and inhibitory activity for tachyphylaxis to clonidine in isolated Guinea-pig ileum," Bioorganic \& Medicinal Chemistry, vol. 9, no. 6, pp. 1499-1507, 2001.

[46] R. Bessalle and D. Lavie, "Withanolide C, A chlorinated withanolide from Withania somnifera," Phytochemistry, vol. 31, no. 10, pp. 3648-3651, 1992.

[47] P. Y. Jia, L. Y. Li, C. Y. Li, and D. W. Song, "Analysis of fatty acid composition of Rosa davurica pall. by gas chromatography-mass spectrometry," Chinese Journal of Biology, vol. 30, pp. 315-319, 2017.

[48] E. Glotter, I. Kirson, A. Abraham, and D. Lavie, "Constituents of Withania somnifera dun-XIII," Tetrahedron, vol. 29, no. 10, pp. 1353-1364, 1973.

[49] I. Kirson, A. Cohen, and A. Abraham, "Withanolides Q and $\mathrm{R}$, two new 23-hydroxy-steroidal lactones," Journal of the Chemical Society, Perkin Transactions 1, vol. 1, no. 21, p. 2136, 1975.

[50] I. Kirson, A. Abraham, and D. Lavie, "Chemical analysis of hybrids of Withania somnifera L. (Dun.). 1. Chemotypes III (Israel) by Indian I (Delhi)," Israel Journal of Chemistry, vol. 16, no. 1, pp. 20-24, 1977.

[51] A. Kumar, M. Ali, and S. Mir, "A new withanolide from the roots of Withania somnifera," Indian Journal of Chemistry (Section B) is a leading monthly journal in Organic and Medicinal Chemistry, vol. 43B, pp. 2001-2003, 2004.

[52] M. Ali, M. Shuaib, and S. H. Ansari, "Withanolides from the stem bark of Withania somnifera," Phytochemistry, vol. 44, no. 6, pp. 1163-1168, 1997.

[53] V. V. Velde and D. Lavie, "A $\Delta 16$-withanolide in Withania somnifera as a possible precursor for $\alpha$-side-chains," Phytochemistry, vol. 21, no. 3, pp. 731-733, 1982.

[54] S. Subramanian and P. D. Sethi, "Chemical components of withania somnifera leaves," Indian Journal of Pharmaceutical Sciences, vol. 32, pp. 16-17, 1970.

[55] L. Misra, P. Lal, R. S. Sangwan, N. S. Sangwan, G. C. Uniyal, and R. Tuli, "Unusually sulfated and oxygenated steroids from Withania somnifera," Phytochemistry, vol. 66, no. 23, pp. 2702-2707, 2005.

[56] B. Jayaprakasam, G. A. Strasburg, and M. G. Nair, "Potent lipid peroxidation inhibitors from Withania somnifera fruits," Tetrahedron, vol. 60, no. 13, pp. 3109-3121, 2004.

[57] L. Misra, P. Mishra, A. Pandey, R. S. Sangwan, and N. S. Sangwan, "1,4-dioxane and ergosterol derivatives from Withania somnifera roots," Journal of Asian Natural Products Research, vol. 14, no. 1, pp. 39-45, 2012.

[58] I. Rautela, M. D. Sharma, N. Sharma, K. Kishor, K. Singh, and N. Sharma, "Comparative GC-MS analysis of leaf and root extract of medicinal plant Withania somnifera," World 
Journal of Pharmaceutical Research (WJPR), vol. 7, pp. 956-972, 2018.

[59] S. Gulati, V. K. Madan, S. Singh, I. Singh, and Dusyant, "Chemical and phytochemical composition of ashwagandha (Withania somnifera L.) roots," Asian Journal of Chemistry, vol. 29, no. 8, pp. 1683-1686, 2017.

[60] A. Bhatia, S. K. Bharti, S. K. Tewari, O. P. Sidhu, and R. Roy, "Metabolic profiling for studying chemotype variations in Withania somnifera (L.) Dunal fruits using GC-MS and NMR spectroscopy," Phytochemistry, vol. 93, pp. 105-115, 2013.

[61] T. Dhanani, S. Shah, N. A. Gajbhiye, and S. Kumar, "Effect of extraction methods on yield, phytochemical constituents and antioxidant activity of Withania somnifera," Arabian Journal of Chemistry, vol. 10, pp. S1193-S1199, 2017.

[62] B. Ganguly, N. Kumar, A. H. Ahmad, and S. K. Rastogi, "Influence of phytochemical composition on in vitro antioxidant and reducing activities of Indian ginseng [Withania somnifera (L.) dunal] root extracts," Journal of Ginseng Research, vol. 42, no. 4, pp. 463-469, 2018.

[63] A. Hameed and N. Akhtar, "Comparative chemical investigation and evaluation of antioxidant and tyrosinase inhibitory effects of Withania somnifera (L.) dunal and Solanum nigrum (L.) berries," Acta Pharmaceutica, vol. 68, no. 1, pp. 47-60, 2018.

[64] T. Tebeka Simur, "Phytochemical investigation and antioxidant activity of leaf extract of Withania somnifera from Konso, South Ethiopia," Oriental Journal of Chemistry, vol. 34, no. 4, pp. 1824-1831, 2018.

[65] N. Alam, M. Hossain, M. A. Mottalib, S. A. Sulaiman, S. H. Gan, and M. I. Khalil, "Methanolic extracts of Withania somnifera leaves, fruits and roots possess antioxidant properties and antibacterial activities," BMC Complementary and Alternative Medicine, vol. 12, no. 1, p. 8, 2012.

[66] N. Alam, M. Hossain, M. I. Khalil, M. Moniruzzaman, S. A. Sulaiman, and S. H. Gan, "High catechin concentrations detected in Withania somnifera (ashwagandha) by high performance liquid chromatography analysis," BMC Complementary and Alternative Medicine, vol. 11, no. 1, p. 8, 2011.

[67] S. S. Chaurasia, S. Panda, and A. Kar, "Withania somnifera root extract in the regulation of lead-induced oxidative damage in male mouse," Pharmacological Research, vol. 41, no. 6, pp. 663-666, 2000.

[68] H. Samir, M. S. Abbas, A. S. Soliman, and R. A. Lotfy, "Phytochemical screening, antioxidant and cytotoxic activities of some plants species derived from the northwestern coast of Egypt," Research Journal of Pharmaceutical, Biological and Chemical Sciences, vol. 9, pp. 82-94, 2018.

[69] P. G. Mwitari, P. A. Ayeka, J. Ondicho, E. N. Matu, and C. C. Bii, "Antimicrobial activity and probable mechanisms of action of medicinal plants of Kenya: Withania somnifera, Warbugia ugandensis, Prunus africana and Plectrunthus barbatus," PLoS One, vol. 8, no. 6, Article ID e65619, 2013.

[70] H. Humaira Rizwana, A. A. Al Hazzani, A. I. Shehata, and N. M. S. Moubayed, "Antibacterial potential of Withania somnifera L. against human pathogenic bacteria," African Journal of Microbiology Research, vol. 6, no. 22, pp. 48104815, 2012.

[71] N. M. AbdEislam, S. Ahmad, R. Ullah et al., "Antibacterial assay of Withania somnifera," Journal of Pure and Applied Microbiology, vol. 7, pp. 791-794, 2013.

[72] D. Kumar, S. K. Kashyap, and S. Maherchandani, "Antibacterial activity of some plant extracts," Veterinary Practitioner Bikaner, vol. 10, pp. 148-151, 2009.
[73] S. Datta, N. k. Kumar Pal, and A. K. Nandy, "Inhibition of the emergence of multi drug resistant Staphylococcus aureus by Withania somnifera root extracts," Asian Pacific Journal of Tropical Medicine, vol. 4, no. 11, pp. 917-920, 2011.

[74] S. Pandit, K.-W. Chang, and J.-G. Jeon, "Effects of Withania somnifera on the growth and virulence properties of Streptococcus mutans and Streptococcus sobrinus at sub-MIC levels," Anaerobe, vol. 19, pp. 1-8, 2013.

[75] K. Halamova, L. Kokoska, Z. Polesny, K. Macakova, J. Flesar, and V. Rada, "Selective in vitro growth inhibitory effect of Withania somnifera on human pathogenic bacteria and Bifidobacteria," Pakistan Journal of Botany, vol. 45, pp. 667-670, 2013.

[76] G. Singh and P. Kumar, "Evaluation of antimicrobial efficacy of flavonoids of Withania somnifera L," Indian Journal of Pharmaceutical Sciences, vol. 73, pp. 473-478, 2011.

[77] L. Kambizi and A. J. Afolayan, "Extracts from Aloe ferox and Withania somnifera inhibit Candida albicans and Neisseria gonorrhoea," African Journal of Biotechnology, vol. 7, pp. 12-15, 2008.

[78] K. S. Girish, K. D. Machiah, S. Ushanandini et al., "Antimicrobial properties of a non-toxic glycoprotein (WSG) from Withania somnifera (Ashwagandha)," Journal of Basic Microbiology, vol. 46, no. 5, pp. 365-374, 2006.

[79] D. Tripathi, A. Modi, G. Narayan, and S. P. Rai, "Green and cost effective synthesis of silver nanoparticles from endangered medicinal plant Withania coagulans and their potential biomedical properties," Materials Science and Engineering: $C$, vol. 100, pp. 152-164, 2019.

[80] K. Halkai, J. Mudda, V. Shivanna, V. Rathod, and R. Halkai, "Antibacterial efficacy of biosynthesized silver nanoparticles against Enterococcus faecalis biofilm: an in vitro study," Contemporary Clinical Dentistry, vol. 9, no. 2, pp. 237-241, 2018.

[81] A. C. P. Dias, G. Marslin, G. Selvakesavan, F. Gregory, and B. Sarmento, "Antimicrobial activity of cream incorporated with silver nanoparticles biosynthesized from Withania somnifera," International Journal of Nanomedicine, vol. 10, pp. 5955-5963, 2015.

[82] S. Sumathi and P. R. Padma, "Antioxidant status of different parts of Withania somnifera," Plant Archives, vol. 8, pp. 69-72, 2008.

[83] D. B. Naidoo, A. A. Chuturgoon, A. Phulukdaree, K. P. Guruprasad, K. Satyamoorthy, and V. Sewram, "Withania somnifera modulates cancer cachexia associated inflammatory cytokines and cell death in leukaemic THP-1 cells and peripheral blood mononuclear cells (PBMC's)," BMC Complementary and Alternative Medicine, vol. 18, no. 1, p. 126, 2018.

[84] W. Ahmed, D. Mofed, A.-R. Zekri, N. El-Sayed, M. Rahouma, and S. Sabet, "Antioxidant activity and apoptotic induction as mechanisms of action of Withania somnifera (Ashwagandha) against a hepatocellular carcinoma cell line," Journal of International Medical Research, vol. 46, no. 4, pp. 1358-1369, 2018.

[85] J. Prakash, S. K. Gupta, V. Kochupillai, N. Singh, Y. K. Gupta, and S. Joshi, "Chemopreventive activity of Withania somnifera in experimentally induced fibrosarcoma tumours in Swiss albino mice," Phytotherapy Research, vol. 15, no. 3, pp. 240-244, 2001.

[86] B. Padmavathi, P. C. Rath, A. R. Rao, and R. P. Singh, "Roots of Withania somnifera inhibit forestomach and skin carcinogenesis in mice," Evidence-Based Complementary and Alternative Medicine, vol. 2, no. 1, pp. 99-105, 2005. 
[87] Y. Khadrawy, M. Elhadidy, H. Sawie, and N. Meguid, "Protective effect of ashwagandha (Withania somnifera) against neurotoxicity induced by aluminum chloride in rats," Asian Pacific Journal of Tropical Biomedicine, vol. 8, no. 1, pp. 59-66, 2018.

[88] U. Pingali, R. Pilli, and N. Fatima, "Effect of Withania somnifera extract on mental stress induced changes in hemodynamic properties and arterial wave reflections in healthy subjects," Current Topics in Nutraceutical Research, vol. 11, pp. 151-158, 2013.

[89] R. Udayakumar, S. Kasthurirengan, A. Vasudevan et al., "Antioxidant effect of dietary supplement Withania somnifera L. reduce blood glucose levels in alloxan-induced diabetic rats," Plant Foods for Human Nutrition, vol. 65, no. 2, pp. 91-98, 2010.

[90] K. Shukla, P. Dikshit, R. Shukla, S. Sharma, and J. K. Gambhir, "Hypolipidemic and antioxidant activity of aqueous extract of fruit of Withania coagulans (stocks) dunal in cholesterol-fed hyperlipidemic rabbit model," Indian Journal of Experimental Biology, vol. 52, pp. 870-875, 2014.

[91] A. A. Elkady and E. T. Mohamed, "Possible role of Withania somnifera against gamma radiation induced cardiotoxicity in male albino rats," Pakistan Journal of Zoology, vol. 48, pp. 539-545, 2016.

[92] H. Hosny Mansour and H. Farouk Hafez, "Protective effect of Withania somnifera against radiation-induced hepatotoxicity in rats," Ecotoxicology and Environmental Safety, vol. 80, pp. 14-19, 2012.

[93] A. Ayer, A. Zarjou, A. Agarwal, and R. Stocker, "Heme oxygenases in cardiovascular health and disease," Physiological Reviews, vol. 96, no. 4, pp. 1449-1508, 2016.

[94] T. Hussain, I. Fatima, M. Rafay et al., "Comparison of antibacterial potential from leaves and fruits of different herbs and shrubs of family Solanaceae," International Journal of Agriculture and Biology, vol. 17, no. 6, pp. 1249-1254, 2015.

[95] E. Zahran, E. A. Abd El-Gawad, and E. Risha, "Dietary Withania sominefera root confers protective and immunotherapeutic effects against Aeromonas hydrophila infection in Nile tilapia (Oreochromis niloticus)," Fish \& Shellfish Immunology, vol. 80, pp. 641-650, 2018.

[96] R. Dutta, R. Khalil, R. Green, S. S. Mohapatra, and S. Mohapatra, "Withania somnifera (ashwagandha) and withaferin A: potential in integrative oncology," International Journal of Molecular Sciences, vol. 20, no. 21, p. 5310, 2019.

[97] Q. X. Ng, W. Loke, N. X. Foo et al., "A systematic review of the clinical use of Withania somnifera (Ashwagandha) to ameliorate cognitive dysfunction," Phytotherapy Research, vol. 34, no. 3, pp. 583-590, 2020.

[98] K. Chandrasekhar, J. Kapoor, and S. Anishetty, "A prospective, randomized double-blind, placebo-controlled study of safety and efficacy of a high-concentration full-spectrum extract of ashwagandha root in reducing stress and anxiety in adults," Indian Journal of Psychological Medicine, vol. 34, no. 3, pp. 255-262, 2012.

[99] D. Shilpi and Y. K. Sharma, "A clinical trial for efficacy of ashwagandha extract in stress related disorders and general index of quality of life," International Ayurvedic Medical Journal, vol. 4, pp. 1-6, 2016.

[100] S. P. Jahanbakhsh, A. A. Manteghi, S. A. Emami et al., "Evaluation of the efficacy of Withania somnifera (Ashwagandha) root extract in patients with obsessive-compulsive disorder: a randomized double-blind placebo-controlled trial," Complementary Therapies in Medicine, vol. 27, pp. 25-29, 2016.

[101] S. Nayak, S. Nayak, B. K. Panda, and S. Das, "A clinical study on management of stress in type-2 diabetes mellitus (Madhumeha) with ashwagandha (Withania somnifera)," An International Journal of Research in AYUSH and Allied Systems (AYUSHDHARA), vol. 2, pp. 413-417, 2015.

[102] C. Andrade, A. Aswath, S. K. Chaturvedi, M. Srinivasa, and R. Raguram, "A double-blind, placebo-controlled evaluation of the anxiolytic efficacy ff an ethanolic extract of Withania somnifera," Indian Journal of Psychiatry, vol. 42, pp. 295-301, 2000.

[103] J. M. Gannon, J. Brar, A. Rai, and K. N. R. Chengappa, "Effects of a standardized extract of Withania somnifera (Ashwagandha) on depression and anxiety symptoms in persons with schizophrenia participating in a randomized, placebo-controlled clinical trial," Annals of Clinical Psychiatry: Official Journal of the American Academy of Clinical Psychiatrists, vol. 31, pp. 123-129, 2019.

[104] K. N. R. Chengappa, C. R. Bowie, P. J. Schlicht, D. Fleet, J. S. Brar, and R. Jindal, "Randomized placebo-controlled adjunctive study of an extract of Withania somnifera for cognitive dysfunction in bipolar disorder," The Journal of Clinical Psychiatry, vol. 74, no. 11, pp. 1076-1083, 2013.

[105] U. Pingali, R. Pilli, and N. Fatima, "Effect of standardized aqueous extract of Withania somnifera on tests of cognitive and psychomotor performance in healthy human participants," Pharmacognosy Research, vol. 6, no. 1, pp. 12-18, 2014.

[106] D. Choudhary, S. Bhattacharyya, and S. Bose, "Efficacy and safety of ashwagandha (Withania somnifera (L.) dunal) root extract in improving memory and cognitive functions," Journal of Dietary Supplements, vol. 14, no. 6, pp. 599-612, 2017.

[107] D. Langade, B. Choudhary, and A. Shetty, "Efficacy of ashwagandha (Withania somnifera [L.] dunal) in improving cardiorespiratory endurance in healthy athletic adults," AYU (An International Quarterly Journal of Research in Ayurveda), vol. 36, no. 1, pp. 63-68, 2015.

[108] J. Sandhu, B. Shah, S. Shenoy, M. Padhi, S. Chauhan, and G. Lavekar, "Effects of Withania somnifera (Ashwagandha) and Terminalia arjuna (Arjuna) on physical performance and cardiorespiratory endurance in healthy young adults," International Journal of Ayurveda Research, vol. 1, no. 3, pp. 144-149, 2010

[109] T. Ziegenfuss, A. Kedia, J. Sandrock, B. Raub, C. Kerksick, and H. Lopez, "Effects of an aqueous extract of Withania somnifera on strength training adaptations and recovery: the STAR trial," Nutrients, vol. 10, no. 11, p. 1807, 2018.

[110] P. V. Nalini, K. S. Manjunath, K. SunilKumarReddy, and P. Usharani, "Evaluation of the analgesic activity of standardized aqueous extract of Withania somnifera in healthy human volunteers using hot air pain model," Journal of Clinical and Diagnostic Research, vol. 1, pp. 1-6, 2019.

[111] G. S. H. Ramakanth, C. Uday Kumar, P. V. Kishan, and P. Usharani, "A randomized, double blind placebo controlled study of efficacy and tolerability of Withaina somnifera extracts in knee joint pain," Journal of Ayurveda and Integrative Medicine, vol. 7, no. 3, pp. 151-157, 2016.

[112] R. R. Kulkarni, P. S. Patki, V. P. Jog, S. G. Gandage, and B. Patwardhan, "Treatment of osteoarthritis with a herbomineral formulation: a double-blind, placebo-controlled, cross-over study," Journal of Ethnopharmacology, vol. 33, no. 1-2, pp. 91-95, 1991 
[113] B. M. Biswal, A. M. Sulaiman, H. C. Ismail, H. Zakaria, M. I. Jalil Abdul, and K. I. Muhammad, "AOS14 phase II clinical study of combination chemotherapy with herb Withania somnifera (Ashwagandha) in breast cancer," European Journal of Cancer, vol. 48, pp. S8-S9, 2012.

[114] M. Choudhury, R. Chakraborty, and U. R. Chaudhuri, "Optimisation of twin screw extrusion process for production of snack from aswagandha (Withania sominifera) rice (Oryza sativa) and chapra (Fenneropenaeus indicus) for antioxidant effect," British Journal of Applied Science \& Technology, vol. 4, no. 9, pp. 1334-1352, 2014.

[115] S. Anita, D. Monisha, P. Sundararajan, S. Narasimman, and G. Bharath, "Formulation of Withania somnifera based herbal cookies using response surface methodology," International Research Journal of Pharmacy, vol. 8, pp. 100108, 2017.

[116] N. Pawar, K. Gandhi, A. Purohit, S. Arora, and R. R. B. Singh, "Effect of added herb extracts on oxidative stability of ghee (butter oil) during accelerated oxidation condition," Journal of Food Science and Technology, vol. 51, no. 10, pp. 27272733, 2014.

[117] G. L. Gupta, Rana, and A. C. Withania, "Somnifera (Ashwagandha): a review," Pharmacognosy Reviews, vol. 1, pp. 129-136, 2007.

[118] S. B. Patel, N. J. Rao, and L. L. Hingorani, "Safety assessment of Withania somnifera extract standardized for Withaferin A: acute and sub-acute toxicity study," Journal of Ayurveda and Integrative Medicine, vol. 7, no. 1, pp. 30-37, 2016.

[119] K. Joshi, S. Tavhare, K. Panara, P. Kumar, and K. Nishteswar, "Studies of ashwagandha (Withania somnifera dunal)," International Journal of Pharmaceutical \& Biological Archives, vol. 7, pp. 1-11, 2016.

[120] M. Prasad, K. Gupta, and A. B. Thakar, "Ashwagandha in psychogenic erectile dysfunction: ancillary findings," International Journal of Research in Ayurveda \& Pharmacy, vol. 5, no. 1, pp. 36-40, 2014.

[121] S. Wankhede, D. Langade, K. Joshi, S. R. Sinha, and S. Bhattacharyya, "Examining the effect of Withania somnifera supplementation on muscle strength and recovery: a randomized controlled trial," Journal of the International Society of Sports Nutrition, vol. 12, no. 1, p. 43, 2015.

[122] E. Ernst, "Herbal medicinal products during pregnancy: are they safe?" BJOG: An International Journal of Obstetrics and Gynaecology, vol. 109, no. 3, pp. 227-235, 2002.

[123] S. Al-Qura'n, "Ethnobotanical survey of folk toxic plants in southern part of Jordan," Toxicon, vol. 46, no. 2, pp. 119-129, 2005.

[124] P. C. Prabu and S. Panchapakesan, "Prenatal developmental toxicity evaluation of Withania somnifera root extract in Wistar rats," Drug and Chemical Toxicology, vol. 38, no. 1, pp. 50-56, 2015.

[125] National Institutes of Health, Ashwagandha: MedlinePlus Supplements, National Institutes of Health, Bethesda, MD, USA, 2020. 